Archived version from NCDOCKS Institutional Repository http://libres.uncg.edu/ir/asu/

\title{
Appalachïan
}

B O O N E, N O R T H C A R O L I N A

\section{Thinking About Fit And Donation Format In Cause Marketing: The Effects Of Need For Cognition}

\author{
By: Anthony H. Kerr and Neel Das
}

\begin{abstract}
A cause-related marketing exchange model, investigating product-cause fit, donation format, and the moderating effects of need for cognition (on fit and format) on consumer purchase intentions, is tested. The results suggest that individuals who have a low need for cognition do not display a difference in purchase intentions for different permutations of product-cause fit and donation format. Individuals who have a high need for cognition, by contrast, indicate greater purchase intentions for an exact donation format when the product-cause fit is low, while exhibiting no difference when the product cause fit is high, regardless of the donation format.
\end{abstract}

Anthony H. Kerr \& Neel Das (2013). Thinking about Fit and Donation Format in Cause Marketing: The Effects of Need for Cognition, Journal of Marketing Theory and Practice, $21: 1,103-112$, DOI: 10.2753/ MTP1069-6679210107. Publisher version of record available at: https://www.tandfonline.com/doi/ abs/10.2753/MTP1069-6679210107 


\title{
THINKING ABOUT FIT AND DONATION FORMAT IN CAUSE MARKETING: THE EFFECTS OF NEED FOR COGNITION
}

\author{
Anthony H. Kerr and Neel Das
}

\begin{abstract}
A cause-related marketing exchange model, investigating product-cause fit, donation format, and the moderating effects of need for cognition (on fit and format) on consumer purchase intentions, is tested. The results suggest that individuals who have a low need for cognition do not display a difference in purchase intentions for different permutations of product-cause fit and donation format. Individuals who have a high need for cognition, by contrast, indicate greater purchase intentions for an exact donation format when the product-cause fit is low, while exhibiting no difference when the product cause fit is high, regardless of the donation format.
\end{abstract}

Cause-related marketing (CRM) is defined as "a process of formulating and implementing marketing activities that are characterized by an offer from the firm to contribute a specified amount to a designated cause when customers engage in revenue-providing exchanges that satisfy organizational and individual objectives" (Varadarajan and Menon 1988, p. 60). In the CRM process, the purchaser receives the product offered in addition to the supplemental utility received from the act of contributing to a cause, the seller benefits from the sale, and the cause or charity benefits from the proceeds of the donation. This is normally a winwin situation for each of the participants in this increasingly recurrent form of exchange in the marketplace (Pracejus, Olsen, and Brown 2003-4). Overall, CRM programs have been found to elicit favorable attitudes and purchase intent (Webb and Mohr 1998), influence consumer perceptions of advertisers/marketers (Pracejus, Olsen, and Brown 2003-4), and be effective in heightening consumer perceptions of the long-term image of the participating firm/product and increasing short-term sales (Chang 2008).

Grau, Garretson, and Pirsch (2007) categorize extant CRM research in terms of its focus on (1) individual consumer characteristics, (2) the cause agent (nonprofit organization)

Anthony H. Kerr (Ph.D., Louisiana State University), Visiting Assistant Professor, Appalachian State University, Boone, NC, kerrah@appstate.edu.

Neel Das (Ph.D., Louisiana State University), Assistant Professor of Marketing, Appalachian State University, Boone, NC, dasn@ appstate.edu. characteristics, (3) consequences of CRM campaigns, and (4) structure of CRM campaigns as designed by the sponsoring company. Such a categorization not only initiates an understanding of the structure of CRM academic research but also helps in identifying and addressing issues and gaps in the research stream. This current study specifically looks at two variables in the category of the structure of CRM campaigns designed by the sponsoring company in addition to a variable from the category of individual consumer characteristics to further investigate the effectiveness of CRM campaigns.

The unique contribution of this study relates to the empirical examination of the conjunctive effects of the perceived level of fit between the product and the cause, format of donation request (both relating to the structure of CRM campaigns), and the need for cognition (individual consumer characteristic) on consumer purchase intentions. While some have looked at company-cause fit (e.g., Gupta and Pirsch 2006), cause-brand fit (e.g., Lafferty 2007; Nan and Heo 2007), and retailer-cause fit (Barone, Norman, and Miyazaki 2007), we look at the partnership with a cause at the more general level of a product. An evaluation of the level of fit between a cause and a general product category should serve as a contributory complement, if not an underpinning, to helping explain the likely effects of other fit

The authors acknowledge three anonymous reviewers for their helpful comments. Both authors contributed equally to this paper. 
pairings involving inherent company, brand, and retailer attitudinal and other extraneous biases or influences.

The format of donation request refers to the presentation of the amount from each sale going to the associated cause. Previous CRM research has devoted significant attention to investigate the overall effectiveness of different formats. Grau, Garretson, and Pirsch (2007), in their exploratory research, have looked at the effectiveness of mentioning an exact amount (vis-à-vis other formats) for each product sold, whereas Pracejus, Olsen, and Brown (2003-4) looked at the efficacy of abstract quantifiers (i.e., where almost no information is presented to the consumer in terms of how much the company is donating to the associated cause). No experimental study, however, has specifically looked at the effectiveness of an exact presentation versus an abstract quantifier. We believe that such an examination is necessary because, although an exact format seems to be most preferred by consumers (Grau, Garretson, and Pirsch 2007), there is a predominance of abstract quantifiers in the marketplace (Pracejus, Olsen, and Brown 2003-4).

Finally, this research also introduces the individual variable of need for cognition (henceforth referred to as NFC) as a moderating factor. To our knowledge, no prior research in CRM has looked at NFC as a moderating variable affecting product-cause fit and the amount of donation request on purchase intentions. This examination of the three constructs discussed above and their effects on purchase intentions offer mixed support for the hypotheses presented, and in so doing, reveals additional interesting research opportunities that could provide contributions to cause-related literature.

The remainder of the paper is organized in the following manner. An empirical model is introduced depicting the constructs examined in this study, followed by a discussion of the importance of the constructs chosen and the presentation of hypotheses. Subsequently, the study is presented proceeded by a discussion of the results and the key findings. Finally, the research is concluded by identifying limitations to the study and by proposing future research directions that might further elucidate the mechanisms and effectiveness of CRM programs.

\section{CAUSE-RELATED MARKETING EXCHANGE MODEL}

A cause-related marketing exchange model is presented in Figure 1. As depicted in the model, the level of productcause fit and the format of donation request have a direct effect on purchase intentions of the product supporting a cause. A moderating effect of these two variables on purchase intentions is also depicted. In addition, NFC is illustrated to moderate the effects of the amount of donation request and product-cause fit on purchase intentions.

From a theoretical perspective, there is sufficient literature support to warrant the examination of the constructs selected. Empirical evidence suggests that perceived fit could have a significant effect on consumer choice and product market share (e.g., Samu and Wymer 2009). Similarly, in terms of the format of donation request, different formats influence consumers' purchase judgments and decision choices differently (Chang 2008). Research has also recognized the role of NFC to predict innate tendencies of individuals to elaborate on a message (Cacioppo and Petty 1982). Essentially, high (compared to low) NFC individuals tend to process information in a more careful and elaborate manner and pay less attention to peripheral or superficial cues. Based on the efficacy for a plausible product-cause fit and an exact amount of donation request, we anticipate that high NFC individuals would be more disposed to cause-related programs utilizing such characteristics. Alternatively, individuals with a low NFC are less likely to elaborate the specifics in terms of the level of product-cause fit and the amount of donation request. More detailed analyses of these variables follow.

\section{PRODUCT-CAUSE FIT}

Fit has been defined in social marketing as the perceived link between the firm's product line, brand image, position, or target market and the affiliated cause's image and constituency (Varadarajan and Menon 1988). Becker-Olsen, Cudmore, and Hill (2006), in their research relating to the impact of corporate social responsibility on consumer behavior, mention that fit influences three important cognitive processes: (1) the amount of thought given to a relationship, (2) specific types of thoughts generated, and (3) evaluations of the two objects. In this study, our investigation of fit falls within the realm of specific types of thoughts generated, that is, a low fit is likely to generate negative thoughts and a high fit is likely to generate positive thoughts. A recent example of a low fit generating negative thoughts is the teaming up of KFC and Susan G. Komen for the Cure dubbed as the "Buckets for the Cure" campaign. According to critics and detractors of this campaign, eating fatty foods increases the risk of breast cancer, especially among postmenopausal women (Newman 2011). Alternatively, when Starbucks donated $\$ 2$ (for every pound of Sumatra coffee) to CARE for tsunami relief in Sumatra, 
Figure 1

Cause-Related Marketing Exchange Model

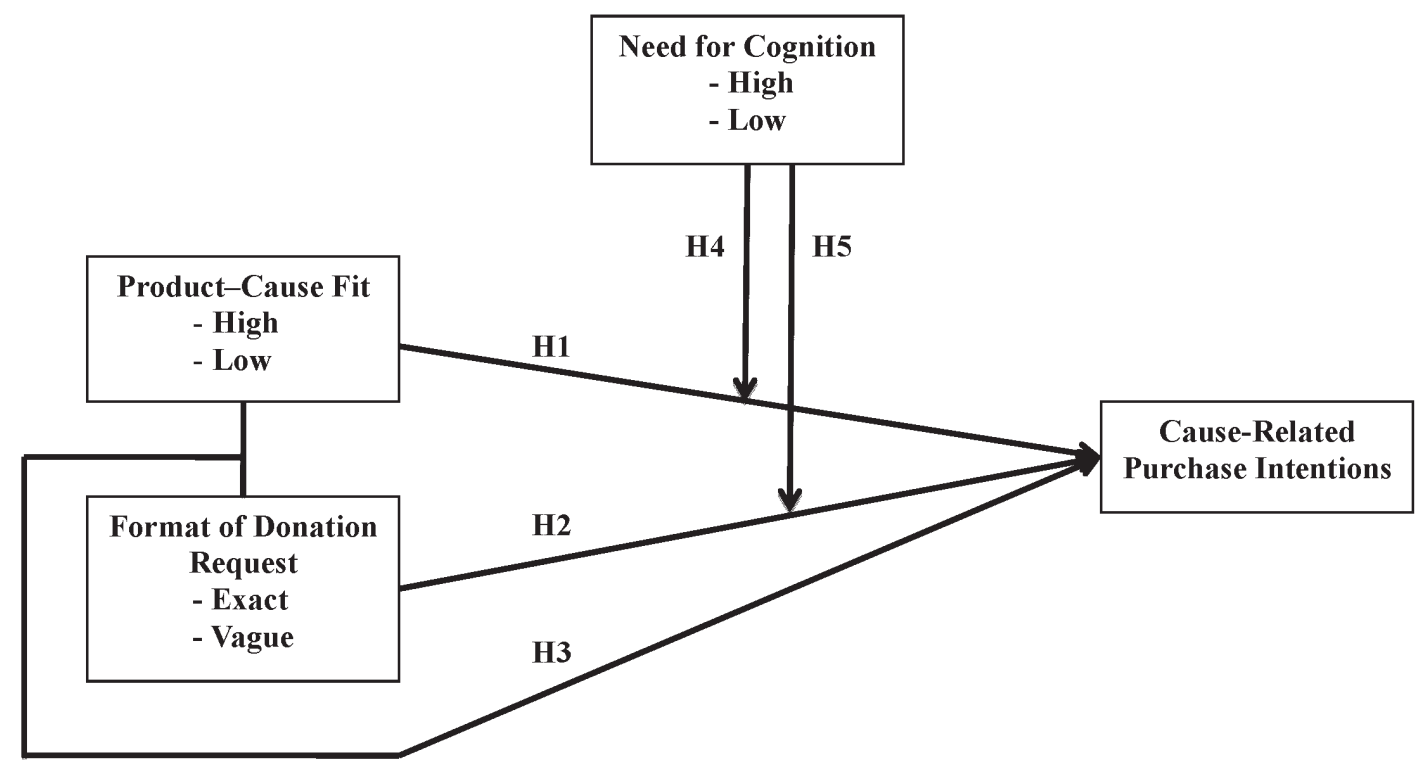

the increase in sales was attributable to the logical alliance between the two (Lafferty 2007).

Research on CRM addresses the issue of fit between a cause and a brand (e.g., Lafferty, Goldsmith, and Hult 2004), a company (e.g., Hoeffler and Keller 2002), a retailer (Barone, Norman, and Miyazaki 2007), and a product (Strahilevitz 1999; Strahilevitz and Myers 1998). According to Strahilevitz and Myers (1998), the effectiveness of CRM programs depends on whether the product sold is frivolous or practical. Frivolous products are those whose consumption results from the objective of gaining sensual pleasure, fantasy, or fun; practical products' consumption results from the objective of satisfying a practical need or a functional task (Chang 2008; Strahilevitz and Myers 1998). Strahilevitz and Myers (1998) found that cause-related promotions paired with frivolous products are more effective than those paired with practical products. As the consumption of a frivolous product results in some level of guilt on the part of the consumer, the concurrent act of donating to a cause is likely to mitigate such feelings of guilt. This particular phenomenon of balancing guilt with a concurrent donation has been termed as "affect-based complementarity" by Strahilevitz and Myers (1998). However, we posit that when a frivolous product is utilized in a cause-related offering and while feelings of guilt may be offset by the concurrent act of assisting a cause, plausible product-cause pairings are also needed to optimally alleviate these feelings of consumer guilt.
The current study looks at the concept of fit as the consumer's perception of the level of compatibility or congruency between the product and the associated cause. Such an embodiment of the fit construct is derived from both branding and advertising literature. For instance, when evaluating brand extensions, consumers who perceive a good fit between the extension and the original product category usually generate positive beliefs, and those who do not perceive a fit generate undesirable beliefs about the extension (Aaker and Keller 1990). Basil and Herr (2003), with respect to co-branding, likened the use of the match-up hypothesis (whereby the effectiveness of a celebrity endorsement is increased when the celebrity is perceived to match-up or fit the product advertised) to the importance of company-cause fit in cause-related promotions. Similarly, Kellaris, Cox, and Cox (1993) found evidence to suggest that music-message congruency can influence ad recall and recognition. When high levels of music-message congruency exist, recall and recognition levels are affected positively and are likely to increase. When congruency levels are low, then the lack of an acceptable link between the music used and the message conveyed becomes a distraction from ad message processing.

In conclusion, based on the conceptual extension of fit as derived from the literature presented, we hypothesize the following:

Hypothesis 1: Those exposed to a higher level of product-cause fit will exhibit higher levels of cause-related 
purchase intentions than those exposed to a lower level of product-cause fit.

\section{Format of Donation Request}

The format of a donation request in the context of the current study is defined as either an exact (a specific dollar amount of each purchase) or a vague (a portion of the purchase) amount of the purchase price going toward the cause. An exact format of donation request is when Procter \& Gamble mentions that it will donate $\$ 4$ from every Tide Loads of Hope vintage T-shirt sold toward helping families affected by disasters. Alternatively, when Troy Healthcare states that it donates a portion of the proceeds to the Arthritis Foundation when people buy their Stopain brand, it is an example of a vague amount of donation request.

Although consumers prefer to know the amount going toward a particular cause (Chang 2008), prior research has found that an overwhelming number of cause-related offers (about 70 percent) were vague in nature (Pracejus, Olsen, and Brown 2003-4). Interestingly, an exploratory study by Grau, Garretson, and Pirsch (2007) found that an exact donation induced the most positive evaluations about the company's CRM efforts and made a company seem most trustworthy. Alternatively, a vague amount induced the least positive evaluations about the company's CRM efforts and made a company seem least trustworthy. In addition to the empirical support mentioned above, further theoretical support for the use of an exact donation amount can also be drawn from the mental imagery literature. Babin, Burns, and Biswas (1992) and MacInnis and Price (1987) found that a concrete (versus an abstract) stimulus could positively enhance, among other things, behavioral intentions.

The apparent anomaly in the findings between Grau, Garretson, and Pirsch (2007) and Pracejus, Olsen, and Brown (2003-4) leads us to question whether the trust and credibility regarding a company's philanthropic efforts arising from an exact (versus a vague) format of donation request result in greater purchase intentions on the part of the consumer. We have not come across any experimental study that specifically examines the difference in purchase intentions for an exact versus a vague format of donation request. Based on the findings of Chang (2008), Grau, Garretson, and Pirsch (2007), and the theoretical support derived from the mental imagery literature, we hypothesize the following:

Hypothesis 2: Those exposed to an exact format of donation request are likely to display higher levels of cause- related purchase intentions than those exposed to a vague format of donation request.

\section{Format of Donation Request and Product-Cause Fit}

When considering a consumer purchase decision, individuals utilize several cues to assess the value of any given purchase option. Cue consistency theory (Maheswaran and Chaiken 1991) states that when using such multiple sources of information, a consistent or corroborating pattern exhibited among the cues is more useful than a disparate or an inconsistent pattern. Specifically, consistent cues yield a cumulative effect where individuals essentially add the values of the cues to form a final evaluation; in contrast, when cues are inconsistent, individuals are likely to focus on the disparate cue and tend to anchor their evaluation from that perspective (Miyazaki, Grewal, and Goodstein 2005).

In the present context of CRM, the cues likely to be used in assessing the value emanating from a cause-related exchange are level of product-cause fit and the format of donation request. Based on the preceding hypotheses relating to the product-cause fit and the format of donation request ( $\mathrm{H} 1$ and $\mathrm{H} 2$, respectively), we suggest that a high product-cause fit and an exact format of donation request is likely to be evaluated more favorably, thereby resulting in greater purchase intentions. In this case, both a high level of product-cause fit and an exact format of donation request represent a consistent, corroborating pattern of positive cues. In contrast, a low product-cause fit and a vague format of donation is likely to be evaluated less favorably because of the presence of a consistent, yet negative, pattern of cues, thereby resulting in lower purchase intentions. Such a phenomenon, termed as "negativity effect," is exhibited since consumers tend to focus on the negative cue or view the negative information as more useful and anchor their subsequent perceptions accordingly. Moreover, in line with Miyazaki, Grewal, and Goodstein (2005), an inconsistent, disparate pattern of cues between the format of donation request and product-cause fit (e.g., a vague [exact] message format and high [low] product-cause fit) is also likely to result in lower levels of purchase intentions among consumers. Hence, the following interaction effect is hypothesized:

Hypothesis 3: Higher levels of purchase intentions are likely to emerge when the product-cause fit is high and the format of donation request is exact. All other combinations of product-cause fit and format of donation request will likely result in lower levels of purchase intentions. 


\section{Need for Cognition}

Enjoyment of and motivation to engage in effortful cognitive information processing is conceptualized as an individual's NFC (Cacioppo and Petty 1982). Essentially, individuals with a high NFC tend to scrutinize communications more closely and are affected more by the cogency of such communications than those with a low NFC (Cacioppo, Petty, and Morris 1983). Extant research illustrates that individuals with a high NFC are more sensitive to message-relevant thoughts, whereas those with a low NFC are more sensitive to peripheral cues (e.g., Haugtvedt, Petty, and Cacioppo 1992).

In terms of our current research, we posit that NFC is likely to moderate the effects of amount of donation request and product-cause fit on purchase intentions. When low NFC individuals are assessing the cause-related offer, peripheral cues in the context of product-cause fit could be the mere alliance of the product with a cause. Similarly, peripheral cues in terms of the amount of donation request could be the mere presence of a cause being supported when buying the product. In both cases, low NFC consumers are likely to assess and evaluate a cause-related program favorably.

For high NFC consumers, the cues used to assess the effectiveness of a cause-related offer are likely to be different. Given their dispositional characteristics regarding message processing, high NFC consumers are more likely to carefully assess and be influenced by the plausibility of the alliance between the product and the cause and the absolute dollar amount going toward a cause. In summary, while low NFC consumers are perhaps more simply affected by the presence of a product offering financial support to a chosen cause, high NFC individuals are likely to consider the nuances of the offer in terms of product-cause fit and amount of donation request in order to develop favorable purchase intentions.

Hence, the following moderating effects of NFC are hypothesized:

Hypothesis 4: When NFC is high, a high (versus low) product-cause fit is likely to result in greater purchase intention levels. Contrarily, when NFC is low, purchase intentions are likely to be the same regardless of productcause fit.

Hypothesis 5: When NFC is high, an exact (versus vague) format of donation request is likely to result in greater purchase intention levels. Contrarily, when NFC is low, purchase intentions are likely to be the same regardless of the format of donation request.

\section{METHOD}

The study featured a 2 (product-cause fit: high versus low) $\times 2$ (format of donation request: exact versus vague) $\times 2$ (NFC: high versus low) between-subjects factorial design in which participants (undergraduate students in the college of business in a medium-size southeastern university) were randomly assigned to each experimental condition. The experiment was done in a classroom setting, and as the students entered the classroom they were handed a questionnaire from a stack that was prescrambled. The first page of the questionnaire laid down the instructions (to carefully read the scenario on the next page and answer the questions that followed) of the study and also indicated that all of the responses were confidential and no one would be identified by way of his or her response. In the next page, the students were instructed to imagine that they entered their local supermarket and subsequently noticed a table display selling boxes of assorted chocolates for $\$ 12$ per box.

The respondents were initially exposed to the productcause fit manipulation. In the high product-cause fit manipulation, the respondents were told that the box of chocolates was supporting the cause of Children's Hunger Fund. In the low product-cause fit manipulation, the respondents were told that the box of chocolates was supporting the cause of Save the Whales. The respondents also read a brief description of the objective of each cause as found on the respective cause Web sites, that is, the Children's Hunger Fund wants to alleviate the suffering of children around the world through the provision of services related to hunger, malnutrition, poor health, abandonment or abuse, while the Save the Whales organization wants to save whales and other marine mammals from predatory fishing and pollution activities.

Consequently, the amount of donation request was manipulated by stating that $\$ 3$ (exact) or a portion (vague) of the sales price would go to the designated cause. NFC was a measured independent variable using the following three items (Ailawadi, Neslin, and Gedenk 2001): "Thinking is not my idea of fun," "I like tasks that don't require much thinking once I have learned them," and "I only think as hard as I have to" ( $1=$ "strongly disagree" to 7 = "strongly agree"; $\alpha=0.73)$. After reading the scenario, the respondents completed items relating to purchase intention, NFC, and the manipulation check questions. Finally, the respondents answered classification questions after which they were debriefed and dismissed.

Purchase intentions were measured by asking the respondents the following questions: "How likely are you to buy the box of assorted chocolates?" ( 1 = "highly unlikely" to 
7 = "highly likely"); "How probable is it that you will buy the box of assorted chocolates?" ( 1 = "highly improbable" to 7 = "highly probable"); "How certain is it that you will buy the box of assorted chocolates?" ( $1=$ "highly uncertain" to 7 = "highly certain"); "What chance is there you will buy the box of assorted chocolates?" ( $1=$ "no chance at all" to $7=$ "very good chance"). The items were averaged to create a purchase intention measure $(\alpha=0.93)$.

One question was used to measure the success of the amount of donation request manipulation. The respondents were instructed to answer the question without referring to the scenario: "Did the scenario mention specifically how much of the purchase price would go toward the cause of the Children's Hunger Fund/Save the Whales?" (response options yes/no). The following two items were used to measure the success of the product-cause fit manipulation (Nan and Heo 2007): "I think that a product in the form of a box of chocolates donating to the cause of the Children's Hunger Fund/Save the Whales represents a good match between the product and the cause" and "I think that donations to the cause of Children's Hunger Fund/ Save the Whales are appropriate for this product category ( $1=$ "strongly disagree" to 7 = "strongly agree").

\section{RESULTS}

A total of 216 students participated in the study for extra credit (50.9 percent female; median age $=22$ ) and correctly answered the manipulation check question regarding the amount of donation request manipulation. Independent sample $t$-tests indicated that a box of chocolates donating to the cause of the Children's Hunger Fund was thought to be a better match $($ mean $=4.60)$ than one donating to the cause of Save the Whales (mean $=2.48 ; t_{(214)}=13.32, p<0.001$ ); similarly, donating to the cause of the Children's Hunger Fund (mean $=4.64$ ) was thought to be more appropriate for the product category of chocolates than donating to the Save the Whales (mean $=2.72 ; t_{(214)}=12.21, p<0.001$ ). Hence, our manipulation for the product-cause fit was perceived as expected.

All the hypotheses were investigated by running a $2 \times 2 \times 2$ analysis of variance (ANOVA) on purchase intentions. H1 stated that higher product-cause fit would result in greater purchase intentions than a lower product-cause fit. The results indicated a significant main effect of productcause fit on purchase intentions $\left(F_{(1,208)}=11.40, p<0.001\right)$. Hence, $\mathrm{H} 1$ was supported. $\mathrm{H} 2$ stated that the use of an exact amount of donation request would result in greater purchase intentions than a vague amount of donation request. The results, however, indicated no significant difference between the two formats of donation request $\left(F_{(1,208)}=3.58\right.$, n.s. [not significant]). Hence, H2 was not supported.

H3 stated that purchase intentions would be greatest for high product-cause fit and exact amount of donation request. Any other combination of product-cause fit and format of donation request would likely result in lower purchase intentions. The results failed to show such an interaction $\left(\mathrm{F}_{(1,208)}=0.537\right.$, n.s. $)$. Hence, $\mathrm{H} 3$ was not supported. H4 stated that for high NFC individuals, significantly greater purchase intentions would be exhibited for a high (compared to a low) product-cause fit. In case of low NFC individuals, there would be no difference in purchase intentions for either level of product-cause fit. No significant interaction was found to support our hypothesis $\left(\mathrm{F}_{(1,208)}=1.40\right.$, n.s. $)$. Hence, $\mathrm{H} 4$ was not supported.

H5 stated that for high NFC individuals, significantly greater purchase intentions would be exhibited for an exact (versus a vague) amount of donation request. For low NFC, there would be no difference in purchase intentions across the two formats of donation request. The ANOVA yielded a significant interaction of amount of donation request and NFC $\left(\mathrm{F}_{(1,208)}=7.70, p<0.01\right)$. As shown in Figure 2, purchase intention was significantly greater for an exact (mean $=3.77)$ versus a vague amount of donation request $\left(\right.$ mean $\left.=2.95, t_{(101)}=3.09, p<0.01\right)$ for high NFC. By contrast, purchase intention was not significantly different for an exact (mean $=3.18$ ) versus a vague amount of donation request $\left(\right.$ mean $=3.31 ; t_{(111)}=-0.52$, n.s.) for low NFC. This supports H3.

Although not hypothesized, we obtained a significant three-way interaction of product-cause fit, donation request format, and NFC on purchase intention $\left(F_{(1,208)}=4.63\right.$, $p<0.05)$ As shown in Figure 3, for low NFC, there was no difference in purchase intention for the levels of productcause fit and donation request format. For high NFC, when product-cause fit was low, a concrete donation format resulted in greater purchase intention (mean $=3.84$ ) than an abstract donation format (mean $=2.49 ; t_{(47)}=3.78$, $p<0.001$ ). Alternatively, when product-cause fit was high, there was no significant difference between a concrete (mean $=3.72)$ and an abstract donation format (mean $=3.40$; $t_{(52)}=0.85$, n.s.).

\section{DISCUSSION}

The overarching goal of our study was to examine the conjunctive effects of two structural variables (i.e., format of donation quantifier and product-cause fit) and an individual consumer characteristic (NFC) in a cause-related context on purchase intentions. Prior research (e.g., Gupta and Pirsch 
Figure 2

Format of Donation Request $\times$ Need for Cognition on Purchase Intentions

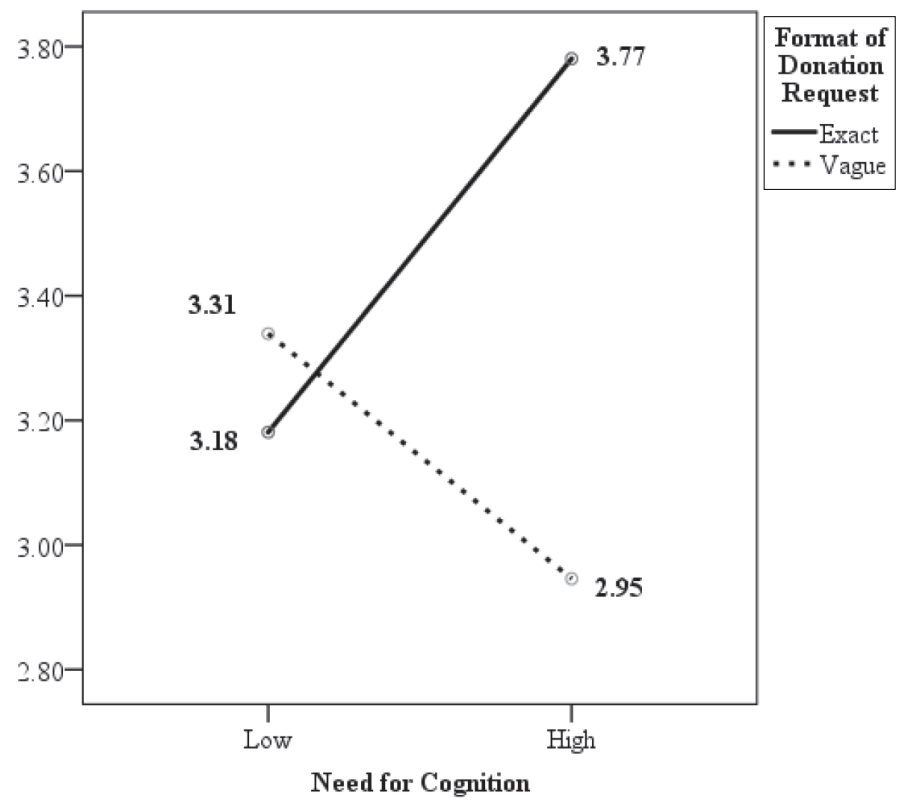

2006; Lafferty 2007) on CRM has essentially conducted a piecemeal examination of the different variables that might affect consumer purchase intentions. If we assume that an individual, when confronted with a CRM promotion, is looking at the factors of a CRM promotion jointly rather than individually, and that one is likely to think about such factors in a varied manner, the importance of this current research becomes salient.

In order to better understand our results, we discuss the main effects first and then analyze the interactions to comprehend the conjunctive effects. Our results indicate that while the main effect of product-cause fit is significant, that of the format of donation request is not (although it is in the anticipated direction with a significance at the 0.06 level). The first result confirms our proposition that even while using a frivolous product in a CRM campaign, it is important to make sure that the cause supported has a plausible link with the product. The second result has interesting connotations. As mentioned earlier, the inspiration for $\mathrm{H} 2$ stemmed from the incongruity between what Pracejus, Olsen, and Brown (2003-4) found (i.e., about 70 percent of cause-related offers, from among 3,414 sites, related to CRM offers, were vague in nature) and what Grau, Garretson, and Pirsch (2007) observed in their exploratory study (i.e., exact donation induced the most positive evaluations about the company's CRM efforts and made a company seem most trustworthy).
Figure 3

Three-Way Interaction of Need for Cognition, Product-Cause Fit, and Format of Donation Request on Purchase Intentions
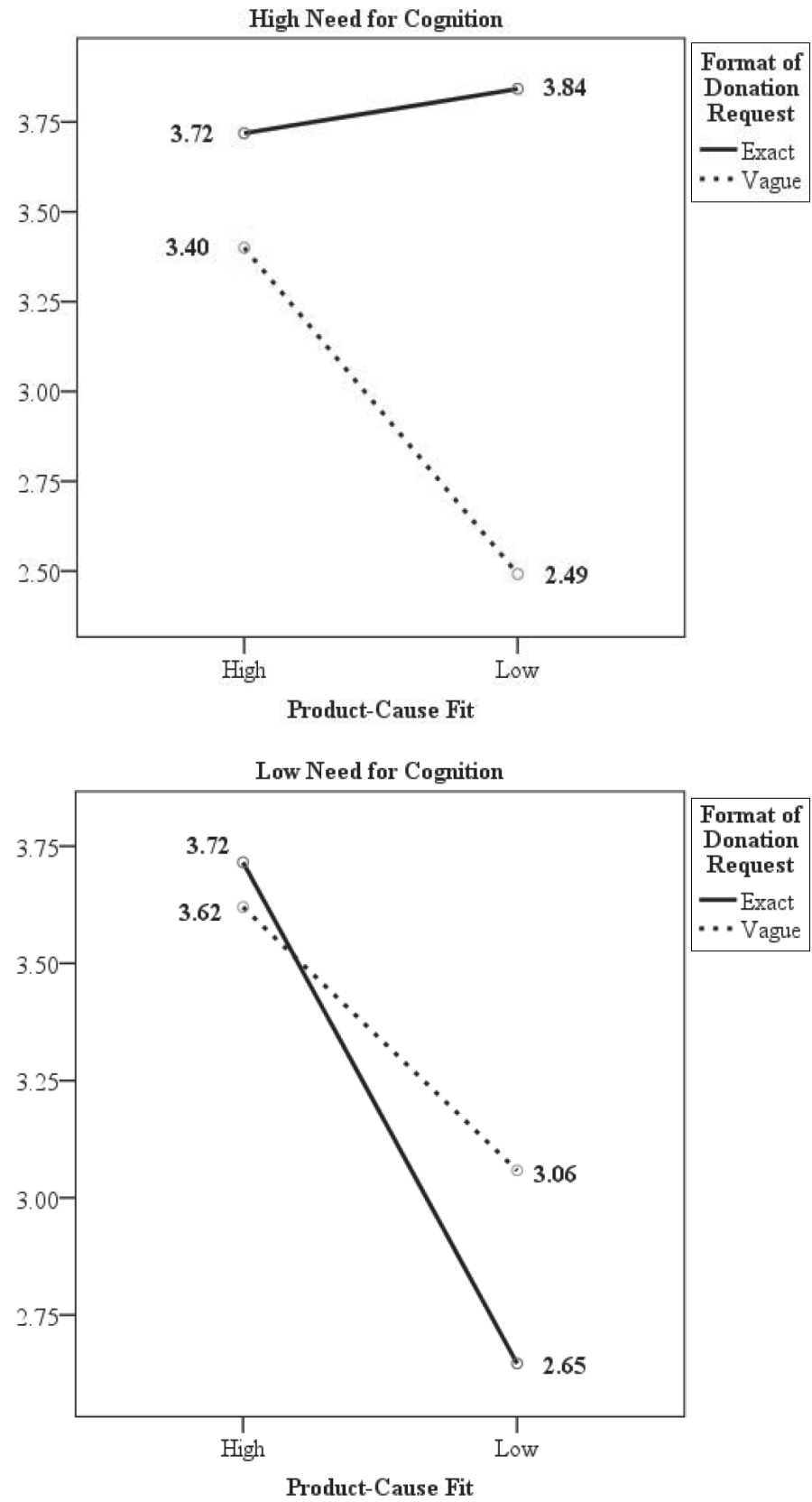

Although Pracejus, Olsen, and Brown (2003-4) did not classify the company sites in terms of the products being sold, Grau, Garretson, and Pirsch (2007) assessed the efficacy of the different donation quantifiers using toothpaste as a product. It may be possible that for a practical product, such as a toothpaste, consumers desire details regarding the donation amount. However, for a frivolous product, such 
as a box of assorted chocolates as used in the current study, consumers are less detail oriented regarding the donation amount. A reason for such a differential preference for the donation amount can be attributed to affect-based complementarity (Strahilevitz and Myers 1998), as introduced earlier. Specifically, any guilt or pleasure arising from the consumption of a frivolous product is likely to be assuaged or complemented by the concurring act of donation to a cause. Hence, while the exact dollar amount might not be important, what is important is that some donation is made to a cause.

The interesting part of the results emerges when we look at the interaction effects. The favorable purchase intentions as exhibited individually for a high (versus a low) product-cause fit and for an exact (versus a vague) donation format seem to disappear when both the structural variables are examined jointly. Specifically, our results show no difference in purchase intentions when examining the interaction of product-cause fit and the format of donation quantifier. We suggested initially, based on cue congruency theory, that a high product-cause fit along with an exact amount of a donation quantifier would lead to greater purchase intentions. But negativity effects arising from other combinations (of the two variables) would likely depress the purchase intention. However, our results indicate no difference in purchase intentions regardless of the combinations of product-cause fit and format of donation request. A reason for our anomalous finding could be due to a boundary condition of the negativity effect. Ahluwalia (2002), for instance, mentioned that the negativity effect is likely to occur when consumers are highly involved in a decision or product category. Within a CRM context, if we assume that consumers are not usually involved with their decision or product category, the negativity effect is then probably eliminated and purchase intentions will be comparable for the different permutations of product-cause fit and format of donation request.

Grau and Folse (2007) looked at the less-involved consumers in terms of donation proximity and message framing. They advocate the use of local causes and a positive message frame for less-involved consumers in order to elicit a favorable evaluation. In particular, Grau and Folse (2007) found that for less-involved consumers, while a local donation increases cause-related participation intentions, a positive message frame alters only the image or perceived value (positively) without affecting the actual behavior. Within the confines of our study, we add to Grau and Folse's research. Particularly, if the stipulation of the boundary effects of cue congruency is admitted, we observe that the efficacy of a high product-cause fit and an exact donation request is nullified assuming that our respondents had low involvement.

To the best of our knowledge, the current research is the first attempt to examine NFC within a CRM context. Our findings support using an exact format of donation request for consumers having a high NFC. On the other hand, NFC did not interact with product-cause fit to affect purchase intentions differentially. A more inclusive understanding of the effects of NFC in our current context is enabled when examining the three-way interaction. What we observe is that when NFC is high, the format of donation request does not differentially affect the purchase intentions for a high product-cause fit; when product-cause fit is low, an exact (compared to a vague) format of a donation request results in greater purchase intention. When NFC is low, purchase intention is not different for the permutations of productcause fit and format of donation request.

Based on the observations as explained above, we cautiously suggest that consumers high in NFC probably consider product-cause fit to be more diagnostic than format of donation request. Maybe this is why high NFC individuals exhibit similar purchase intentions for a high product-cause fit, regardless of the format of donation request. Only when the product-cause fit is low, high NFC individuals consider the format of donation request with an exact (versus a vague) format, resulting in greater purchase intentions. We further posit that probably for low NFC individuals, the mere fact that a product supports a cause is reason enough to participate in a cause-related exchange. As Lafferty (2007) mentions, a support for a cause readily generates a degree of affect that might precede and influence cognitions. Although Lafferty did not investigate NFC, we advocate, based on our results, that possibly such an affect provides an explanation for the behavioral intention of low NFC consumers.

\section{MANAGERIAL IMPLICATIONS}

The managerial implications emanating from this study are proposed in terms of the main and interactive effects of the variables on purchase intention. In particular, a company offering a hedonic product to its target market may be strategically better off linking the offering to a plausible cause and providing the exact amount of donation going toward the cause from each purchase. The three-way interaction obtained provides further guidance if a company wants to better segment the market according to how much individuals enjoy effortful thinking (i.e., NFC). 
For individuals having a higher NFC, the more important variable affecting the intention to participate in a causerelated exchange seems to be product-cause fit. For a high product-cause fit, the purchase intention is not likely to be different for either an exact or a vague format of donation request. As Pracejus, Olsen, and Brown (2003-4) indicate, sometimes there may be some legitimate reasons why marketers choose to run with a vague format. If that is the case, then purchase intentions may probably be optimized when a high product-cause fit is employed. In fact, as our results portray, both high and low NFC individuals react favorably to a high product-cause fit with a vague format of donation request.

Alternatively, if a high product-cause fit is absent, individuals with a high NFC are likely to react more favorably to an exact format of donation request. What is also important to note is that for low NFC individuals, the advantage emanating from an exact format becomes void in the event of a low product-cause fit.

\section{LIMITATIONS AND FUTURE RESEARCH}

As in other empirical research efforts, limitations in our context were recognized and considered. First, a relatively homogeneous, convenience sample of student subjects was used in the study. Inherent concerns in using student respondents relate to generalizability issues, but given their level of consumer socialization development, student samples have proven to be providers of valid consumer behavior data. Importantly, prior CRM research advocates the use of student respondents (Dean 2004). Furthermore, the "2010 Cause Evolution Study" (Cone Communications 2010) indicated that Millennials between ages 18 and 24 , with nearly $\$ 40$ billion in discretionary income, was a much sought after consumer segment. Ninety-four percent of such respondents in the Cone Communications (2010) study found it acceptable for a company to support a cause through marketing. Second, the product stimuli used in the study were fictitious, and while such implementation helped us to garner greater experimental control, it likely presented a lack of realism in regard to shopping experiences. Finally, future research might provide a better picture by assessing actual behavior, rather than evaluating purchase intentions, as was done in the present study.

It certainly appears that ever-increasing research efforts have been and will be devoted to cause-related exchanges. Many extraneous variables may very well come into play when examining cause-related exchanges. Opportunities for research in this area, among other things, may include the impact on purchase intentions by the type of purchase involved-that is, planned (goal-oriented) purchases versus impulse purchases-and the type of product purchasedthat is, utilitarian versus hedonic. In addition, future research objectives may want to investigate the strength or pull of consumer affect toward any cause-related offer. As noted, many additional research opportunities exist, and those mentioned above are but a few of the prevalent conceptual and empirical possibilities.

\section{REFERENCES}

Aaker, David A., and Kevin L. Keller (1990), "Consumer Evaluations of Brand Extensions," Journal of Marketing, 54 (January), 27-41.

Ahluwalia, Rohini (2002), "How Prevalent Is the Negativity Effect in Consumer Environments?" Journal of Consumer Research, 29 (September), 270-279.

Ailawadi, Kusum L., Scott A. Neslin, and Karen Gedenk (2001), "Pursuing the Value-Conscious Consumer: Store Brands Versus National Brand Promotions," Journal of Marketing, 65 (January), 71-89.

Babin, Laurie A., Alvin C. Burns, and Abhijit Biswas (1992), “A Framework for Providing Direction for Research on Communications Effects of Mental Imagery-Evoking Advertising Strategies," in Advances in Consumer Research, vol. 19, John F. Sherry, Jr. and Brian Sternthal, eds., Provo, UT: Association for Consumer Research, 621-628.

Barone, Michael J., Andrew T. Norman, and Anthony D. Miyazaki (2007), "Consumer Response to Retailer Use of Cause-Related Marketing: Is More Fit Better?" Journal of Retailing, 83 (4), $437-445$

Basil, Debra Z., and Paul M. Herr (2003), "Dangerous Donations? The Effects of Cause-Related Marketing on Charity Attitude," Journal of Nonprofit \& Public Sector Marketing, 11 (1), 59-76.

Becker-Olsen, Karen L., Andrew B. Cudmore, and Ronald P. Hill (2006), "The Impact of Perceived Corporate Social Responsibility on Consumer Behavior," Journal of Business Research, 59 (1), 46-53.

Cacioppo, John T., and Richard E. Petty (1982), "The Need for Cognition," Journal of Personality and Social Psychology, 42 (January), 116-131.

_ _ _ and Katherine J. Morris (1983), "Effects of Need for Cognition on Message Evaluation, Recall, and Persuasion," Journal of Personality and Social Psychology, 45 (4), 805-818.

Chang, Chun-Tuan (2008), "To Donate or Not to Donate? Product Characteristics and Framing Effects of Cause-Related Marketing on Consumer Purchase Behavior," Psychology \& Marketing, 25 (12), 1089-1110.

Cone Communications (2010), "2010 Cause Evolution Study," Cone Communications, Boston (available at www.conecomm. com/2010-cone-cause-evolution-study/).

Dean, Dwane H. (2004), "Consumer Perception of Corporate Donation: Effects of Company Reputation for Social Responsibility and Type of Donation," Journal of Advertising, 32 (4), 91-102. 
Grau, Stacy L., and Judith A.G. Folse (2007), "The Influence of Donation Proximity and Message Framing on the Less Involved Consumer," Journal of Advertising, 36 (4), 19-33.

—, Judith A. Garretson, and Julie Pirsch (2007), "Cause-Related Marketing: An Exploratory Study of Campaign Donation Structures Issues," Journal of Nonprofit \& Public Sector Marketing, 18 (2), 69-91.

Gupta, Shruti, and Julie Pirsch (2006), "The Company-CauseCustomer Fit Decision in Cause-Related Marketing," Journal of Consumer Marketing, 23 (6), 314-326.

Haugtvedt, Curtis P., Richard E. Petty, and John T. Cacioppo (1992), "Need for Cognition and Advertising: Understanding the Role of Personality Variables in Consumer Behavior," Journal of Consumer Psychology, 1 (3), 239-260.

Hoeffler, Steve, and Kevin L. Keller (2002), "Building Brand Equity Through Corporate Societal Marketing," Journal of Public Policy and Marketing, 21 (1), 78-89.

Kellaris, James J., Anthony D. Cox, and Dena Cox (1993), "The Effect of Background Music on Ad Processing: A Contingency Explanation," Journal of Marketing, 57 (October), 114-125.

Lafferty, Barbara A. (2007), "The Relevance of Fit in a Cause-Brand Alliance When Consumers Evaluate Corporate Credibility," Journal of Business Research, 60 (5), 447-453.

—, Ronald E. Goldsmith, and G. Tomas M. Hult (2004), "The Impact of the Alliance on the Partners: A Look at Cause-Brand Alliances," Psychology \& Marketing, 21 (7), 509-531.

MacInnis, Deborah J., and Linda L. Price (1987), "The Role of Imagery in Information Processing: Review and Extensions," Journal of Consumer Research, 13 (March), 473-491.

Maheswaran, Durairaj, and Shelly Chaiken (1991), "Promoting Systematic Processing in Low-Motivation Settings: Effect of Incongruent Information on Processing and Judgments," Journal of Personality and Social Psychology, 61 (July), 13-25.
Miyazaki, Anthony D., Dhruv Grewal, and Ronald C. Goodstein (2005), "The Effect of Multiple Extrinsic Cues on Quality Perceptions: A Matter of Consistency," Journal of Consumer Research, 32 (June), 146-153.

Nan, Xiaoli, and Kwangjun Heo (2007), "Consumer Responses to Corporate Social Responsibility (CSR) Initiatives," Journal of Advertising, 36 (2), 63-74.

Newman, Andrew A. (2011), "Good/Corps Aims to Help Business Meet Social Goals," New York Times, May 12 (available at www.nytimes.com/2011/05/13/business/ media/13adco.html?_r=2\&scp=1\&sq=cause\%20related $\% 20$ marketing \&st $=\mathrm{cse} \& /$ ).

Pracejus, John W., G. Douglas Olsen, and Norman R. Brown (2003-4), "On the Prevalence and Impact of Vague Quantifiers in the Advertising of Cause-Related Marketing (CRM)," Journal of Advertising, 32 (4), 19-28.

Samu, Sridhar, and Walter Wymer (2009), "The Effect of Fit and Dominance in Cause Marketing Communications," Journal of Business Research, 62 (4), 432-440.

Strahilevitz, Michal (1999), "The Effects of Product Type and Donation Magnitude on Willingness to Pay More for a Charity-Linked Brand," Journal of Consumer Psychology, 8 (3), 215-241.

—, and John G. Myers (1998), "Donations to Charity as Purchase Incentives: How Well They Work May Depend on What You Are Trying to Sell," Journal of Consumer Research, $24(4), 434-446$.

Varadarajan, P. Rajan, and Anil Menon (1988), "Cause-Related Marketing: A Coalignment of Marketing Strategy and Corporate Philanthropy," Journal of Marketing, 52 (July), 58-74.

Webb, Deborah J., and Lois A. Mohr (1998), "A Typology of Consumer Responses to Cause-Related Marketing: From Skeptics to Socially Concerned," Journal of Public Policy and Marketing, 17 (2), 226-238. 